\title{
ESCOLAS TÉCNICAS AGRÍCOLAS: UM ESTUDO SOBRE ENSINO DE MATEMÁTICA E FORMAÇÃO DE PROFESSORES
}

\section{Technical Education related to Agricultural affairs: some remarks on teachers preparation and mathematics education}

\author{
Maria Ednéia Martins-Salandim ${ }^{1}$ \\ Antonio Vicente Marafioti Garnica ${ }^{2}$
}

Resumo: Valendo-se da metodologia da História Oral, este artigo pretende estudar a formação de professores de Matemática e suas práticas relativas ao ensino de Matemática em Escolas Técnicas Agrícolas. Com base em uma síntese histórico-sociológica sobre o panorama rural brasileiro, a constituição do ensino técnico e o desenvolvimento do ensino técnico agrícola, este artigo defende que as escolas técnicas agrícolas sofrem uma dupla marginalização: por um lado, proveniente de sua natureza profissionalizante, e, por outro, dada sua vinculação com o meio campesino. Tal marginalização ocupa também o interior das escolas, onde os professores de Matemática executam uma coreografia de resistências e acomodações em relação aos professores das áreas técnicas e, de modo geral, ao sistema regular de ensino.

Palavras-chave: Escolas Técnicas Agrícolas. História da educação matemática brasileira. Formação de professores. Ensino de Matemática.

Abstract: The central focus of this paper is to establish that the Brazilian Education Programa to prepare professionals in Technical-Agricultural Schools is suffering a kind of marginalization which comes from two distinct perspectives: the intention to prepare professionals (being a branch of Technical Education) and the relationship to the countryside (a community space historically seen as peripheral in its relation to urban culture). The paper discusses - from a historical and sociological point of view and using Oral History as methodological approach - the experiences of Math's teachers in their daily struggles against some conceptions of other teachers (mainly those of technical areas) and against all the "regular" schooling system.

Keywords: Technical-Agricultural schooling system. History of Brazilian mathematics education. Teachers formation. Math's teaching and learning.

\footnotetext{
${ }^{1}$ Licenciada em Matemática. Doutoranda em Educação Matemática. Professora substituta, Departamento de Matemática, Universidade Estadual Paulista "Júlio de Mesquita Filho", Unesp, campus de Bauru, SP, Brasil. $<$ edneia_martins@yahoo.com.br>

${ }^{2}$ Bacharel em Matemática. Livre-docente. Docente, Departamento de Matemática, Faculdade de Ciências, Unesp campus de Bauru, SP, Brasil.<vgarnica@fc.unesp.br>
} 


\section{Introdução}

Este artigo sintetiza algumas das compreensões resultantes de um trabalho de pesquisa voltado a compreender - sobretudo com base em um viés histórico - as práticas e a formação de professores que atuaram em Escolas Técnicas Agrícolas no Estado de São Paulo, dando especial ênfase às questões relacionadas ao ensino de Matemática (MARTINS-SALANDIM, 2007). Ao estudo das escolas técnicas - considerada a produção da educação e, especialmente, da educação matemática - tem sido dada pouca atenção pelos especialistas. $\mathrm{Na}$ área em que mais propriamente nos inscrevemos - a educação matemática - conhecemos apenas uma referência prévia (PINTO, 2006) que se dispõe a estudar, especificamente, essa modalidade de ensino.

Em nossa pesquisa chamou a atenção um certo espectro de marginalidade que envolve o ensino técnico e, mais fortemente, o ensino técnico agrícola. Na verdade, ponderamos que a modalidade de formação agrícola, do ponto de vista histórico, envolve uma dupla marginalidade: aquela de pertencer ao ensino técnico aliada à resistência - tornada usual - quanto às práticas relativas ao campo. Certamente se trouxermos essa discussão para nossos dias esse espectro de marginalidade estará mais diluído, dada a importância que a produção agrícola vem ocupando, cada vez mais, na economia e na política do mundo contemporâneo. O mesmo também se aplica ao estudo das escolas técnicas, que toma um rumo bastante distinto após a industrialização, que assume, no século XX, patamares antes apenas imagináveis por poucos.

Nosso trabalho tem, como aliados, o levantamento bibliográfico e o método da História Oral. Tomando por base oito entrevistas realizadas com professores de matemática e administradores escolares que atuaram, em meados do século XX, nas mais antigas escolas agrícolas do Estado de São $\mathrm{Paulo}^{3}$, pretendemos registrar alguns elementos para constituir uma história da educação e da educação matemática que ressaltasse a formação desses professores, suas formas de atuação, as especificidades dessas escolas e seu histórico de constituição. Esses depoimentos nos permitiram configurar o ambiente dessas escolas e nos encaminharam para uma busca bibliográfica destinada a aprofundar algumas compreensões e retroceder a um passado mais distante do que aquele no qual nossos depoentes viveram suas experiências.

Esse exercício de investigação nos levou a optar pelo conceito de marginalidade ${ }^{4}$ (SCHMITT, 2001) como o principal organizador de nossas percepções sobre o Ensino Técnico Agrícola. É a marginalidade o único eixo possível? Certamente não. Este tema é um dentre os eixos que podem nos auxiliar.

\footnotetext{
${ }^{3}$ Escolas Técnicas Agrícolas de Espírito Santo do Pinhal, São Manuel, Presidente Prudente, Jacareí e Jaboticabal.

${ }^{4}$ Em "A história dos marginais", Schmitt (2001) possibilita escaparmos das imagens mais usuais - porque midiáticas - vinculadas ao termo marginal. $\mathrm{O}$ autor - que lança as bases de uma história da marginalidade, defendendo a necessidade de sua existência, amplia o significado de "marginal" ao discutir como os que são inscritos nessa condição vão tendo suas posições sociais (ou os modos como são vistos) alteradas de acordo com as profissões que desempenham e os locais e épocas em que vivem.
} 
Outros leitores, com outras experiências, outras leituras e, portanto, outras perspectivas, poderão encontrar - mesmo tendo como base os mesmos depoimentos e obras consultadas - outro fio condutor para que o movimento de análise ocorra e um cenário se descortine.

Mais especificamente, o que disparou nossa opção pelo conceito de marginalização como categoria central nas análises foi percebermos, a partir das entrevistas com nossos colaboradores, a proximidade entre Ensino Técnico Agrícola e delinquência. Essa proximidade mostrou-se, sobretudo, por conta de algumas políticas públicas cujas estratégias de efetivação incluíam transformar essa modalidade de ensino em reformatórios juvenis destinados à recuperação moral de crianças e adolescentes a partir do vínculo com as atividades campesinas. A esta informação aliou-se, por conta das revisões bibliográficas, a compreensão dos mecanismos de exclusão e assistencialismo que historicamente caracterizaram o Ensino Técnico, e, ainda, as pesquisas prévias que havíamos realizado acerca das escolas rurais no interior do estado de São Paulo (GARNICA e MARTINS, 2006; MARTINS, 2003).

Se, por um lado, esse conjunto de compreensões nos levou a configurar o Ensino Técnico Agrícola como uma realidade educacional vitimada por uma dupla marginalidade ser "técnico" e voltado às questões do campo -; por outro lado, nossa imersão nessa questão nos levou a detectar uma outra dicotomia nesse plano de relações entre marginalidade e Ensino Técnico Agrícola: foi possível abordar essa marginalidade a partir de dois pontos de vista complementares, mas distintos - o externo e o interno.

O ponto de vista interno trata de circunscrever as práticas realizadas pelos professores e alunos em suas escolas, em suas salas de aula, em relação a outros conteúdos, outros professores e outras instituições de ensino, de modo a perceber os mecanismos de exclusão, vigentes no interior das escolas, a que foram submetidas algumas práticas, e como os atores deste cenário atuaram para reverter ou conviver com estes mecanismos. Do ponto de vista externo, por sua vez, tentamos compreender o ensino técnico em sua dimensão histórica, sua constituição e as legislações sob as quais funcionaram. Certamente os pontos de vista externo e interno interagem a todo momento, e talvez por isso essa nossa dissociação possa parecer, em princípio, artificial. Julgamos, entretanto, que essa é uma estratégia interessante e adequada para traçar um panorama de tal modo que a marginalidade possa ser realçada quando estudando as Escolas Técnicas Agrícolas e sua proximidade com as questões relacionadas ao meio camponês. Uma ressalva em relação à abordagem interna, porém, é necessária: talvez a questão da marginalidade - percebida a partir dos embates cotidianos vividos e relatados por nossos depoentes professores de matemática - não fosse ressaltada se nossos entrevistados fossem os técnicos agrícolas, agrônomos ou engenheiros que também atuavam nesses núcleos de ensino. O conflito de posições mostra-se mais flagrantemente, cremos, exatamente por conta da necessidade, sentida pelos professores de matemática, de adaptar-se a uma modalidade de ensino que privilegiava as questões técnicas e práticas "naturalmente" mais próximas de outros profissionais que com eles atuavam.

Neste artigo, privilegiaremos a abordagem interna - em que se ressalta a especificidade do ensino de matemática - ainda que uma síntese da visão externa esteja presente com a intenção de contextualizar o leitor. 


\section{O Ensino Técnico Agrícola: uma síntese de sua constituição e desenvolvimento}

Para estimular a aprendizagem e o desenvolvimento das práticas de trabalho necessárias à sociedade em formação, em meados do século XIX tornou-se compulsória, para crianças e jovens sem opção quanto à profissão ou ofício, a frequência a instituições específicas: é $\mathrm{o}$ início da formação profissional. E o preconceito em relação tanto à condição de escravo quanto a alguns ofícios tidos como "menores" ou impróprios à condição de homem livre deslizou para essa formação obrigatória. Os estabelecimentos militares foram os primeiros a utilizarem, no Brasil, os menores órfãos e desvalidos como matéria-prima humana para uma formação sistemática da força de trabalho.

A desvalorização dos trabalhos manuais não é recente e nem somente um fenômeno brasileiro. No Brasil, desde o período da colonização os trabalhadores livres fugiam das atividades artesanais dada a vinculação dessas práticas à mão de obra escrava. Afastar-se delas, portanto, era uma exigência para que não pairassem dúvidas quanto à condição social de quem as realizava. Esta situação era ainda mais complexa para os negros livres, uma vez que seus traços étnicos não contribuíam para a pretendida distinção sociocultural. Dessa forma, os trabalhos manuais passaram a ser vistos como desonrosos por sua destinação, em geral, aos escravos. Muitos ofícios e trabalhos manuais surgiram, no Brasil, por conta da formação de agrupamentos urbanos, seja devido à agroindústria açucareira ou à mineração. Entretanto, muitos homens livres eram avessos também a esses ofícios, dada a relação que se mantinha entre esses fazeres e a condição de escravo (ainda que, por exemplo, a mecanização da agricultura exigisse trabalhadores qualificados e disciplinados - o que, julgava-se, não se encontraria entre escravos). Segundo Cunha (2005a), a criação das escolas de aprendizes artífices foi um marco para o ensino profissional da Primeira República, ainda que a maior motivação não fosse a formação de força de trabalho qualificada para as indústrias e, sim, abrigar desfavorecidos, habilitando-os para o trabalho, com preparo técnico e intelectual.

Com o processo da libertação dos escravos, a questão que preocupava os intelectuais do Império era como fazer os trabalhadores livres trabalharem, já que não se poderia lançar mão da coação física: era preciso educá-los para que o trabalho passasse a ser visto como um dever (CUNHA, 2005a, 2005b). Assim, as propostas de ensino profissional para as massas, no período imperial, estiveram pautadas na concepção de moralização e desenvolvimento da sociedade sem, no entanto, alterarem sua estrutura.

Buscando eliminar o preconceito quanto a algumas dessas atividades, ações foram implementadas ainda nesse período. Mas esta era uma questão difícil já que a modalidade de formação para o trabalho vinculou-se ao atendimento de órfãos e desvalidos e que, mesmo no período pós-abolição, quando a condição de escravo foi formalmente extinta, o direito ao nãotrabalho - ao ócio - continuava garantido apenas aos ricos, com o que o trabalho se aproximava à pena por alguma transgressão.

No início do período republicano, as instituições de ensino profissional começaram a divulgar, com maior veemência, seu afastamento em relação à filantropia, ainda que a inferiorização da condição social e econômica fosse mantida como critério para a classificação dos candidatos às vagas nas instituições. As instituições salesianas destacaram-se por sua proposta de transformarem "crianças pobres e órfãs em trabalhadores tecnicamente qualificados e im- 
buídos de uma disciplina laboriosa [...]" (CUNHA, 2005a, p. 53). Na década de 1940, algumas dessas instituições fecharam e outras, por um período, recebiam menores enviados pelo Serviço de Assistência ao Menor (SAM), que também foi extinto com a justificativa de que esses jovens não tinham orientação vocacional. Esta foi uma marca de marginalidade herdada pelo ensino agrícola, como revelaram alguns de nossos depoentes.

$\mathrm{Na}$ esteira da criação dos cursos técnicos, surgiram os patronatos agrícolas, instituições voltadas ao atendimento de crianças e adolescentes abandonados ou infratores, tendo como objetivo precípuo o ensino de noções de agricultura e alfabetização.

De acordo com Cunha (2005b), as iniciativas para criação do ensino agrícola são anteriores às relativas ao ensino industrial, e são oriundas das elites brasileiras. As primeiras iniciativas de implantação do ensino agrícola de grau médio foram destinadas às elites, mas, posteriormente, voltaram-se as atenções para o nível superior, relegando o ensino secundário às classes menos favorecidas, sendo este um período no qual percebemos as distintas destinações do ensino no Brasil: formação em nível superior destinada às elites e formação técnica destinada às classes dos trabalhadores, para qualificação da mão de obra.

Del Priore e Venâncio (2006) discutem algumas tentativas de implantar o ensino agrícola, afirmando que essas iniciativas sempre estiveram pautadas em interesses econômicos, visando a estabelecer técnicas específicas para a melhoria da produção brasileira, privilegiando os grandes proprietários de terras, dadas as possibilidades do mercado exterior, já que os pequenos proprietários desenvolviam agricultura e pecuária de subsistência.

Analisar o modo como a cultura rural brasileira foi se constituindo é fundamental para compreendermos especificidades do ensino agrícola como um "espaço marginal" entrelaçado às marginalidades que revestem o ensino técnico. Para isso, naturalmente, vem à cena a dicotomia cidade/campo.

No caso brasileiro, percebemos que esta dicotomia campo-cidade vai ocorrer mais claramente com o processo de industrialização, quando se intensifica a urbanização. No entanto, encontramos indícios de marginalidade de alguns setores rurais ainda no período colonial. De acordo com Del Priore e Venâncio (2006) vários textos de viajantes estrangeiros do período colonial apontam que muitas foram as relações tecidas entre ócio e pobreza quando se falava dos homens do campo, pois as condições de vida e trabalho nem sempre se identificavam com os padrões europeus, particularmente aqueles criados a partir da Revolução Industrial. Por outro lado, para Holanda (2006), no Brasil, as cidades coloniais se constituíram com algumas particularidades, o que as diferencia de outras cidades européias ou mesmo americanas. Para ele, ao contrário da regra geral segundo a qual a prosperidade dos meios urbanos fezse à custa da produção agrícola, no Brasil a posse da terra não se concentrou primeiro nas mãos dos representantes de classes urbanas. Uma vez que a sociedade colonial não teve suas bases em espaços urbanos, Holanda (2006) destaca que, nesse período, membros da elite rural eram recrutados para ocupar cargos e funções importantes nas cidades, ainda que residentes em áreas rurais. O autor destaca, ainda, o perfil bastante particular da formação das cidades brasileiras, que se viam em uma situação de dependência diante dos domínios agrários, constituídos pelos grandes proprietários rurais.

A estrutura rural brasileira sempre teve como base o latifúndio, com predominância da monocultura de produtos como cana e café ou a extração de minérios destinados à exportação. Tal estrutura nos permite perceber um cenário inicial responsável pelo desenvolvimento 
de uma visão preconceituosa em relação ao homem rural. Este preconceito desenvolve-se particularmente em relação àqueles homens e mulheres - não somente ex-escravos - que se afastavam das regiões mais povoadas, durante o período colonial e que, com os avanços da campanha abolicionista, dirigiam-se para regiões de fronteira agrícola ${ }^{5}$.

Estes deslocamentos podem ser entendidos como fuga das condições de subemprego nas grandes fazendas e como expressão de um desejo de tornarem-se, os evadidos, pequenos proprietários. As atividades rurais desenvolvidas nessas regiões fronteiriças, por um lado, não atendiam aos interesses da metrópole - por não terem como função abastecê-la, uma posição inadequada à colônia - e, por outro lado, também não eram vistas com bons olhos pelos fazendeiros - que perdiam cada vez mais as oportunidades de mão-de-obra barata e abundante. Tais interesses contribuíram para o desenvolvimento e divulgação de um preconceito quanto aos campesinos.

Este preconceito estabeleceu-se a partir da defesa de um ponto de vista que julgavam tais comunidades rurais avessas aos processos civilizadores (dentre eles, a educação). Era portanto urgente que a elite tomasse a frente para reverter o processo, criando estratégias, como, por exemplo, a implantação de instâncias formadoras específicas, elaborando inclusive políticas de Estado com a intenção de regenerar esses indivíduos. O Ministério da Agricultura do Império incorporou a crença de que por meio da educação poderia se regenerar a mão-deobra do campo, uma regeneração vinculada tanto aos efeitos negativos da escravidão quanto ao crescente desejo de autonomia (vista como ilegítima e perigosa) gerado pela imensa fronteira agrícola existente.

O isolamento dos que migravam para as zonas de fronteira agrícola contribuía para a manutenção da tensão entre a elite detentora do poder político e econômico e esses migrantes, promovendo preconceito. Esse preconceito em relação aos evadidos, no entanto, não era apenas por viverem distantes dos aglomerados populacionais, mas uma recriminação que escondia sua motivação mais profunda: o problema na redução da disponibilidade de mão-de-obra.

O deslocamento do rural em direção ao urbano, especialmente devido às novas oportunidades de trabalho, ocorreu mais intensamente a partir de meados do século XX. Com isso, passa a ocorrer uma maior participação do homem do campo na vida econômica e social das cidades, o que acaba contribuindo para a redução das diferenças que separam esses dois agrupamentos. Isso, entretanto, não eliminou os antagonismos entre ambos os "espaços", dado que permanecem inalteradas as características próprias de cada contexto, seja em relação às atividades básicas ou à mentalidade. Nas comunidades rurais ainda pesam muito tanto a cultura tradicional quanto o "apego" a métodos obsoletos de exploração agrícola, havendo maior resistência à adoção de novas técnicas, quer por respeito à tradição quer pela falta de habilitação para aplicá-las. Ainda que a cidade seja considerada polo de civilização, em seu interior convivem as culturas rural e urbana, uma vez que parte dessa urbe tem origens rurais. Como a população da cidade foi "recrutada" no campo, onde ainda persistia um modo próprio de

\footnotetext{
${ }^{5}$ Áreas não utilizadas para a produção de exportação e que, em geral, estavam distantes do litoral e dos pequenos aglomerados populacionais, como os engenhos de açúcar. 
vida, não encontraremos, de imediato, variações abruptas e descontínuas entre o urbano e o rural, que são dois polos de fixação humana. Ambas se influenciam, mais intensamente a cidade sobre o campo, já que com o êxodo rural sua população reduziu-se muito. Mas o desequilíbrio ou desnível entre o urbano e o rural torna-se cada vez mais intenso devido: ao modo distinto como o capitalismo age nas cidades (aglomerando, compactando) e no campo (dispersando); ao progresso e à acessibilidade relativos tanto de equipamentos técnicos quanto às iniciativas culturais nas cidades, o que motiva a procura por melhores salários e a ilusória melhoria nas condições de vida. Segundo Candido (2003), o distanciamento entre a cultura rural e a urbana foi determinado pela diferenciação de níveis econômicos, mas com "a industrialização, a diferenciação agrícola, a extensão do crédito, a abertura do mercado interno" (p. 279), entretanto, ocorre uma reaproximação social e geográfica da cidade com o campo.

O preconceito por nós percebido e que contribui para a marginalização do ensino agrícola refere-se mais propriamente às atividades rurais desempenhadas por aqueles que, além de desempenhá-las, residem em zonas rurais. Com a evolução industrial, o trabalho torna-se cada vez mais técnico e especializado, e a civilização (em geral, "as cidades") passa a ser tecnológica.

Assim, o ensino técnico agrícola vincula-se a dois grandes estigmas profundamente marginalizadores em suas origens: ser técnico e estar relacionado às atividades campesinas.

\section{O cotidiano das escolas técnicas agricolas}

Foi possível auscultar o "interior" da escola agrícola com base nos depoimentos que coletamos dos professores $^{6}$ que nela atuaram nas décadas de 1950 e 1960; e se continuamos a ter como parâmetro certos aspectos de marginalização - agora resgatados a partir de análises sobre o cotidiano dos professores - devemos apontar que nossa percepção desses aspectos nem sempre implicam (ou implicaram ou são implicados por) situações de inércia e submissão, sendo diversas as "subversões" desenvolvidas nas escolas agrícolas destinadas a reverter ou a conviver com esse (e nesse) cenário por nós caracterizado como marginal.

A partir do nosso eixo de análise buscamos explicitar como compreendemos alguns elementos dos depoimentos coletados para esta pesquisa. Os depoentes falaram das motivações para iniciarem, permanecerem e se desvincularem das escolas agrícolas. Em relação à formação, relatam tanto a formação básica, realizada no Normal ou no Científico, quanto aquela desenvolvida em cursos complementares ou da Licenciatura. É também em relação à formação que percebemos alguns vieses da atuação desses professores, o modo como lidavam com os docentes das áreas técnicas, com a direção e com os recursos (in)disponíveis. Do período em que permaneceram nas escolas agrícolas, os depoentes nos falaram: de suas práticas em relação aos conteúdos de matemática a serem ensinados, do significado da disciplina

${ }^{6}$ Carlos Eduardo Mangili, Cid Haroldo Corrêa, Edith Lopes Tecedor, Elda Birraque Faraco, Madalena Mutsumi Tanaka Takahashi, Maria Aparecida Peres França, Noriko Meguro e Oduvaldo da Costa César. 
Martins-Salandim, M. E.; Garnica, A. V. M.

nos cursos agropecuários, da estrutura da escola e dos alunos que frequentavam esses estabelecimentos de ensino, cujo objetivo se confundia entre o assistencialismo e a preparação de mão-de-obra especializada para atividades agropecuárias.

\section{Espaços de atuação}

Algumas escolas aproveitaram a estrutura das fazendas nas quais foram instaladas. Em Presidente Prudente, por exemplo, a escola foi implantada na antiga colônia da fazenda e, em Jaboticabal, utilizou-se a estrutura do Patronato Agrícola anteriormente existente. Dessa forma, as antigas construções que abrigavam os colonos e as antigas celas do Patronato transformaram-se em alojamentos para os alunos que lá permaneciam numa dinâmica de internato.

O internato foi relatado como um benefício para os alunos, sendo determinante para os de menor poder aquisitivo, oriundos de diversas regiões do país - e, até mesmo, de outros países, como Bolívia e Japão. Alguns desses alunos raras vezes retornavam para suas casas durante a realização do curso. Nesses alojamentos só residiam meninos, o que pode ter contribuído para o reduzido número de meninas em cursos agrícolas, sendo que, em algumas escolas e por um determinado período, era exclusiva a presença masculina. Ainda que a Lei Orgânica do Ensino Agrícola ${ }^{7}$ de 1946 previsse a presença feminina na escola agrícola, recomendava-se que essa participação das meninas se efetivasse apenas em instituições de exclusiva frequência. Com o curso ginasial, a frequência de meninas passou a ser notada, ainda que continuasse a ser bem menor que a masculina.

Para as meninas, algumas escolas ofereciam cursos específicos, como o de economia doméstica. Para professoras e alunas do Curso Normal que iriam atuar em escolas rurais, também eram oferecidos cursos específicos. A professora Elda realizou um desses cursos e a professora Maria Peres recordou-se que várias de suas colegas do curso Normal também os frequentaram. Em Presidente Prudente, o sr. Cid ministrou cursos da CADES (Campanha de Aperfeiçoamento e Difusão do Ensino Secundário) para professoras que iriam atuar no ensino típico rural, em parceria com a Delegacia de Ensino do município.

A quase exclusividade à frequência masculina pode também ser notada em relação ao quadro dos profissionais que atuavam nessas escolas. A professora Maria Aparecida relatou que, em Espírito Santo do Pinhal, ela foi a primeira mulher a atuar na escola agrícola como professora, e que só aos poucos esse número aumentou. Para ela, os modos femininos de lidar com os alunos foram bem aceitos. Professor Oduvaldo, de Jaboticabal, também comentou sobre o reduzido número de professoras no ensino agrícola, situação que aos poucos foi se modificando.

O afastamento das mulheres do sistema escolar não é um tema recente. E há que se considerar a proximidade das escolas agrícolas com outra forma de afastamento e exclusão: aquela relativa aos menores delinquentes.

${ }^{7}$ Decreto-lei n. 9.613, de 20 de agosto de 1946. 
Quanto a este aspecto de centro correcional, as escolas agrícolas, em geral instaladas em áreas rurais, ainda que próximas às cidades, podem ter sido percebidas, por técnicos ligados a órgãos de governo, como um local privilegiado para que menores delinquentes pudessem ser recuperados - via afastamento e aprendizagem de uma profissão. Mas o envio desses menores às escolas, em geral - como pudemos perceber pelos depoimentos que coletamos sem prévio conhecimento dos profissionais que atuavam nesses centros educacionais, nem sempre ocorreu sem transtornos: os professores viam nesses menores uma ameaça ao bom comportamento dos demais alunos e, ainda mais, como uma possibilidade de enfoque equivocado à instituição, já que poderia alterar (ou permitir que fossem vistos de forma distorcida) seus objetivos de formar profissionais para a agricultura e pecuária.

Os alunos sabiam que as regras eram rígidas e que a desobediência a elas poderia acarretar expulsão. Mas as maiores dificuldades de adaptação à escola ocorreram com os alunos enviados ao sistema agrícola por meio de um convênio com órgãos da justiça como, por exemplo, o SAM: para alguns dentre esses meninos, a desistência ou fuga do curso foi a solução. A partir de trâmites gerenciados por esses órgãos, menores, em geral de grandes cidades como São Paulo, Belo Horizonte e Rio de Janeiro, por um ano, foram enviados para algumas escolas agrícolas no final da década de 1950.

Nossos depoentes destacaram as escolas localizadas em Presidente Prudente e em São Manuel como participantes desse convênio com o SAM. Como o regime era de internato, mas sem restrição de liberdade de saída do prédio, alguns alunos fugiam por não se adaptarem ou à profissão proposta pelo curso ou ao regime ali estabelecido. A intenção divulgada como justificativa para essa parceria Sistema Agrícola - Secretaria da Justiça, era que, longe de sua região de domínio, em atividades de lida com a terra, os menores infratores tomariam gosto pelas atividades e adquiririam uma profissão ligada à agricultura e à pecuária. No entanto, podemos também perceber que, na prática, a ideia era afastar os menores de suas regiões e do contato com o crime: um processo assistencialista com doses de moralização. Teria sido o sistema agrícola escolhido devido a uma tendência de se perceber o homem do campo como dócil?

Em Jaboticabal a situação era semelhante, sendo que, por um bom tempo, a escola recebeu alunos órfãos ou carentes enviados por promotores públicos. Chegavam apresentados por uma carta-atestado comprovando que o menor - ou sua família - tinha algum vínculo com atividades agrícolas. A eles também era necessária a adaptação ao regime existente. A maioria dos alunos da escola agrícola de Jaboticabal era carente, mas via, no estudo, uma possibilidade de melhorar de vida. Em São Manuel, a professora Elda afirma que a maioria dos alunos era proveniente da zona rural e de famílias de baixo poder aquisitivo, o que inclusive contribuía para que a escola urbana fosse mais conceituada. Como nem todos conheciam o trabalho realizado nessas escolas e como era mínima a divulgação positiva em relação às práticas do ensino agrícola, havia certa preferência pelas escolas da cidade.

A dificuldade da reintegração dos menores por meio das escolas agrícolas, entretanto, não está necessariamente ligada à indisposição daqueles que ali atuavam. Ao discutir a situação dos ciganos que, ao transitarem por cidades e aldeias a caminho de Roma, eram rejeitados, mesmo tendo à mão salvo-condutos do imperador, do rei, ou mesmo do papa, Schmitt (2001) considera que a ideia do medo, superior a salvo-condutos, faz fracassar qualquer tentativa de reintegração. Também Elias (2000), pela via da Sociologia, trata das tramas da exclusão e da marginalização. Seu Estabelecidos e Outsiders, entretanto, não se aplica à nossa análise porque não 
tratamos de uma comunidade pequena e relativamente "limitada", como é Winston Parva - o reduto inglês onde Elias conduziu sua pesquisa - e nem podemos contar, em nosso estudo, com a homogeneidade de classe social, origem e situação financeira como a que Elias detectou na comunidade por ele estudada. No caso das escolas agrícolas, a não integração dos menores dava-se por vários motivos, além dessa não aceitação pela comunidade que residia naquela região. Como exemplo, podemos citar a imposição de uma determinada formação (a da escola agrícola) como parte da pena (imposta por lei) como um dos possíveis causadores da inadaptação àquela estrutura.

Essa noção de marginalização parece ser adequada para entendermos, ao menos em parte, o que ocorria nas escolas agrícolas tanto em relação aos profissionais que ali atuavam quanto em relação à pouca procura da escola pela população local.

Nota-se que essa não valorização (para não falarmos em desvalorização) da escola agrícola local refere-se apenas aos estudos, pois muitas vezes parece que moradores da cidade na qual a escola estava instalada reconheciam a importância de uma escola que promove eventos e ajuda a prover a feira das cidades com produtos de qualidade. Estas atividades podem ser compreendidas como tentativas de atenuar esse preconceito, promovendo maior divulgação do trabalho realizado pela escola. Em Presidente Prudente, promovia-se a venda de produtos cultivados na escola numa feira muito popular na cidade. Além disso, organizavam atividades esportivas e sociais para interação entre os estudantes, havendo também as comemorações específicas, como formaturas, as quais, além da presença dos profissionais da escola, contavam com a participação de autoridades da cidade e, algumas vezes, de representantes da Secretaria da Agricultura que vinham de São Paulo. Também os bons desempenhos dos alunos em olimpíadas, campeonatos ou gincanas contribuíram para a propagação de uma boa imagem da escola.

A preferência por escolas urbanas em regiões nas quais as escolas agrícolas estavam instaladas justifica-se tanto por preconceitos oriundos desse histórico de marginalidade do ensino técnico quanto pelo desejo que os membros das comunidades rurais têm de ocupar funções urbanas. Por outro lado, algumas dessas comunidades, em alguns momentos, parecem ter buscado a formação oferecida por essas escolas em suas regiões. Em Presidente Prudente, por um período, foi intensa a presença de descendentes de japoneses. Para o professor Cid, o grande número de alunos desta nacionalidade deveu-se à influência do senhor Shigueo Mizoguchi $^{8}$ sobre a colônia de japoneses, por ser, também ele, descendente. A região agrícola desse município era formada por pequenas propriedades de japoneses, que então enviaram seus filhos para o curso de liderança rural, cujo objetivo era ensinar técnicas agrícolas para serem aplicadas em suas propriedades. Já em Pinhal, segundo a professora Maria Aparecida, um grande número de alunos descendentes de holandeses buscou a escola no período em que a fazenda Holambra foi formada.

\footnotetext{
${ }^{8}$ Shigueo Mizoguchi, agrônomo, foi diretor da Escola Técnica Agrícola de Presidente Prudente, tendo, posteriormente, assumido a Diretoria Estadual do Ensino Agrícola de São Paulo. 
Os alunos, de modo geral, foram considerados atenciosos e estudiosos, sendo que o empenho nos estudos foi destacado como determinante para o bom andamento e reconhecimento do ensino ministrado nessas escolas. O bom comportamento que imperava na escola é destacado como fator determinante para os rendimentos alcançados nos estudos. Os alunos que ingressavam nos cursos agrícolas, nas modalidades iniciais - como o curso de liderança rural em Presidente Prudente -, não precisavam ter o curso primário. A alfabetização era realizada em uma escola primária municipal, instalada dentro da própria fazenda da escola agrícola, que atendia também aos filhos dos trabalhadores rurais residentes nas proximidades. Com a criação de escolas de Iniciação Agrícola, muitos alunos que passavam por ali buscavam escolas maiores, nas quais já funcionassem cursos ginasiais, para continuar os estudos. Nessas escolas de Iniciação Agrícola o primário era desenvolvido em apenas dois anos. Mas nem todas as escolas criadas entraram em funcionamento.

Foi possível perceber pelos depoimentos que, em algumas escolas agrícolas, ocorreu primeiro a implantação e funcionamento de cursos específicos e que, posteriormente, sua formatação e direcionamento passaram a ocorrer via legislação. As reformas foram narradas pelos professores com reserva. Ressaltaram, quando muito, que a falta de orientações específicas - ou o modo como foram implantadas - penalizaram aqueles que, efetivamente, deveriam executá-las.

A dinâmica do ensino agrícola não se deveu apenas aos modos internos de se pensar o conhecimento ali necessário e às influências da parte prática sobre a propedêutica, mas, fundamentalmente, por conta das interferências legais, que, de modo desarticulado, propunham alterações nesse sistema de ensino. Alguns de nossos depoentes apontaram que houve uma queda significativa na qualidade do ensino agrícola a partir da década de 1970, momento em que também os professores que entrevistamos estavam se desvinculando das funções docentes. A partir desse momento, a direção foi assumida por profissionais que não eram da área agrícola ou pecuária. Para o senhor Cid, com a inclusão do ginásio - e depois do colegial -, a finalidade agrícola dos cursos - a essência dessa formação - foi negligenciada. Percebe-se nisso também um jogo de forças, uma vez que os cargos vinculados diretamente à administração das escolas possibilitavam a condução da organização do ensino segundo as áreas de interesse e domínio dos administradores. Perdas e ganhos são percebidos: se o diretor fosse agrônomo eram dados ênfase e privilégio às partes técnicas; já se o diretor fosse da área educacional, sua compreensão da área agrícola era mais limitada.

As escolas funcionavam em período integral - manhã e tarde -, sendo que, num desses períodos, aconteciam as aulas teóricas, tanto técnicas quanto propedêuticas e, no outro, as aulas práticas. O período noturno era destinado aos estudos. Em alguns cursos específicos, como o de liderança rural, em Presidente Prudente, as aulas eram apenas no período noturno, com as atividades práticas sendo desenvolvidas apenas durante o dia. As aulas no período noturno abrangiam alfabetização, matemática elementar e noções de agricultura, ministradas pelo engenheiro agrônomo Shigueo Mizoguchi e pelo veterinário Cid Haroldo Corrêa. Só após alguns anos iniciou-se a contratação de professores específicos para cada área.

Em Presidente Prudente funcionou o projeto "Aliança para o Progresso", que possibilitou a aquisição de vários implementos agrícolas, verbas, materiais e veículos pela escola. Esse projeto fez parte de um programa de ajuda econômica e social à América Latina, encabeçado pelos Estados Unidos da América entre 1961 e 1970. 
Outros benefícios foram tratados, nos depoimentos, como importantes nessas escolas: a existência de médicos, dentista, boa alimentação, cooperativa, e a estratégia didáticopedagógica de permitir aos alunos o exercício do processo desde o plantio e cuidado no desenvolvimento da produção até as negociações para as vendas de suas produções. Além do mais, em algumas escolas, o dinheiro adquirido com as vendas era dividido, parte dele servindo para auxiliar na manutenção da escola; parte depositada para cada aluno em conta bancária. Esses valores eram sacados por esses alunos quando do término do curso.

Esse modelo de cooperativa foi expandido para todo o sistema agrícola pelo senhor Shigueo Mizoguchi, por meio do Plano Agrícola Orientado (PAO), em 1965. Esse plano foi implantado quando já funcionavam os cursos ginasiais agrícolas, nos quais apenas um período era reservado às aulas. Essa iniciativa deveu-se às experiências do professor Shigueo, em cursos realizados em Porto Rico, e, também, às da época em que era diretor da escola de Presidente Prudente. O sistema também funcionava em Jaboticabal.

Nesse sistema de cooperativa, o envolvimento do aluno era intenso, pois além de se envolver com a produção, buscando alternativas para superar os problemas (como os dias de muito frio e neblina que prejudicavam as plantações, por exemplo) também precisavam de bom preparo em outras matérias para conseguirem boas negociações para a compra e a venda de produtos. Esse estímulo relativo à preparação dos alunos agrícolas contribuía para a ocultação de uma outra face desse sistema: deixava para a escola a responsabilidade por sua sustentação. A necessidade de produzir para garantir a manutenção da escola possibilitava o deslize para a utilização da mão-de-obra dos alunos em detrimento de uma formação técnica adequada.

Tais mecanismos nem sempre eram percebidos pelos profissionais da escola. Os depoimentos destacaram mais a dedicação, integração e idealismos dos professores, funcionários e direção como ingredientes importantes para o desenvolvimento da escola agrícola e o bom desempenho das práticas de ensino e formação profissional que nelas ocorriam. Era com essa diversidade de contexto e necessidades de adequação que o professor de Matemática deparava-se e com a qual convivia, ainda que isso nem sempre fosse um fator ressaltado nos relatos dos que vivenciaram essa realidade, por curtos ou longos períodos.

\section{Magistério: início, permanência e desligamento}

Nossos professores depoentes iniciaram e encerraram suas passagens pela escola agrícola de modos distintos, sendo que, dentre eles, a primeiro a assumir aulas em escolas desta modalidade foi a professora Elda Birraque, em São Manuel, no início da década de 1950; e a última a se desvincular foi a professora Madalena Mutsumi Tanaka Takahashi, que se aposentou no ano de 2006 no Colégio Técnico Agrícola de Jaboticabal.

Pelos depoimentos coletados para esta pesquisa, percebemos que os professores iniciaram suas atividades docentes em escolas agrícolas ou foram atuar nesse sistema de ensino muito cedo, mesmo tendo passado por outras escolas. A passagem pela escola agrícola é relatada, em geral, sem referências aos aspectos de marginalidade por nós percebidos: não havendo vagas em escolas urbanas, esse era um espaço a mais para que professores do ginásio - e, posteriormente, do segundo grau - iniciassem suas carreiras. 
O ingresso nas escolas agrícolas, em geral, ocorreu motivado por um convite específico, de um ex-professor ou conhecido ou, ainda, por conta de a família do recém-formado possuir contatos que ou motivaram o convite ou possibilitaram ao professor saber da existência de vaga na escola. Inicialmente, as aulas eram de substituição e, muitas vezes, a substituição tornou-se efetivação no cargo. Alguns professores prestaram concurso para ingresso ou efetivação, e outros foram efetivados por meio de legislação, quando o ensino agrícola foi transferido para a Secretaria da Educação.

O ensino agrícola, diferentemente do que ocorria com a escola rural não era tomado, geralmente, como ponto de partida inevitável da carreira (embora fosse uma possibilidade a mais) (Martins, 2003). Estas instituições estavam localizadas em algumas regiões específicas e bem determinadas e, em geral, próximas das cidades. Com exceção da professora Madalena, os demais professores estiveram ligados a apenas uma escola agrícola - aquela instalada em seu município.

Diversos foram os motivos que levaram os professores depoentes a se desligarem do ensino agrícola. Essa quebra de vínculo, porém, não se deveu à procura de uma escola melhor, mas, na maioria das vezes, devido a limitações e instabilidades no número de aulas, pelo menos no que diz respeito às disciplinas propedêuticas, como o caso da matemática. Essa redução acarretaria uma outra queda: a salarial.

Parece que a marginalidade do ensino agrícola, do ponto de vista interno, foi um elemento motivador para um comprometimento coletivo destinado a ultrapassar ou eliminar tal estigma, o que favoreceu o desenvolvimento dessa modalidade de ensino, uma vez que havia um empenho declarado em tornar respeitados tanto o ensino agrícola quanto as demais escolas vinculadas a essa modalidade de formação. Por outro lado, as alterações advindas dos órgãos gerenciadores sempre se sobrepuseram às iniciativas internas a essas escolas.

A introdução do segundo grau aumentou o número de aulas e, com isso, as possibilidades para os professores. No entanto, com a extinção do ginásio agrícola, a opção preferencial parece ter sido a de migrar para o ensino regular, no qual o número de aulas era maior. Nesse sentido é que a marginalidade desse sistema de ensino é ainda marcante nas décadas de 1960 e 1970: atendia um número reduzido de alunos e era equivocadamente gerenciado segundo diretrizes propostas para o ensino regular.

A realidade dessas escolas era específica e contava com alunos com diversas formações e origem, o que intensificava a complexidade para a atuação do professor. É nesse cenário particular que atuaram os professores depoentes em nossa pesquisa, cuja formação básica em nada difere da formação de professores que atuaram em escolas urbanas.

O início da carreira no magistério nestas escolas, em geral, dava-se com formação normalista e/ou no científico, passando por cursos complementares e aperfeiçoamentos creditados à própria prática. Não havia preparação mínima diferenciada para aqueles que atuariam nessas escolas. A especificidade exigida do professor de matemática para atuar em escolas agrícolas era obtida atuando nas escolas agrícolas.

Essa perspectiva de formação (na e pela) prática aplica-se ao professor de modo geral, não apenas aos que atuaram nas escolas agrícolas. De acordo com Baraldi (2003), em sua pesquisa sobre formação de professores secundários na região de Bauru nas décadas de 1960 e 1970, percebe-se que, 
Martins-Salandim, M. E.; Garnica, A. V. M.

[...] a formação inicial do professor de Matemática [...] deu-se na prática cotidiana de uma sala de aula. Muitas vezes norteando-se pela prática de seus antigos professores, os docentes ministravam suas aulas tal como foram por eles vivenciadas anteriormente: (re)articulavam suas posições de alunos. Muitos dos conceitos matemáticos que precisaram ensinar aprenderam sozinhos, "perguntando aqui e ali". (BARALDI, 2003, p. 234)

\section{Formação e atuação do professor de matemática: recursos e adequações}

Com base nos depoimentos, podemos apontar alguns "estágios" na formação do professor de Matemática que atuava no ensino agrícola. Destacamos quatro "etapas" desta formação: básica, intermediária, inicial e na prática.

A formação básica foi realizada no curso Científico e/ou Normal, em escolas da cidade onde residiam à época. Como não havia, nas décadas de 1950 e 1960, exigência do curso Normal para atuar como professor, ao se concluir o Científico também já era possível lecionar?. Essa etapa da formação era de extrema importância, uma vez que após sua conclusão já se iniciava a atividade da docência, sendo esta uma prática que também ocorria no sistema de ensino regular, e não apenas no ensino agrícola, como já apontado em outras pesquisas (GAERTNER, 2004; GALETTI, 2004; BARALDI, 2003).

Alguns professores fizeram ambos os cursos, Normal e Científico, em busca de uma formação mais ampla ou visando à adequação a alguma legislação.

Ainda que algumas situações escolares na formação básica não tenham sido muito positivas em relação à matemática, ocorreu, em um dado momento, com alguns professores, uma reconciliação com esta disciplina, que passa a ser encarada com mais naturalidade. Essa nova postura diante dos conteúdos de matemática foi influenciada ou por um professor ou no próprio processo de lecionar matemática. Para outros, no entanto, a facilidade em lidar com a disciplina parece ter sido uma constante. Independente dessas primeiras relações com a matemática serem de afastamento ou aproximação, o desempenho como professor é relatado como satisfatório, pois, quando necessário, realizavam estudos complementares e/ou orientações com outros profissionais.

A formação em geral, e em matemática especificamente, foi relatada pelos depoentes a partir dessas experiências positivas ou negativas em relação a conteúdos e de acordo com o convívio com seus professores. Uma maior cobrança e trabalho intenso com a matemática "teórica" que se pudesse lecionar essa disciplina posteriormente, inclusive para o segundo grau, sem ter

\footnotetext{
${ }^{9}$ Ressalte-se que, em outras regiões e/ou em outros períodos, os professores iniciavam sua atuação ainda sem esta formação ou equivalente.

${ }^{10}$ Por Matemática "teórica” entendemos que os depoentes estejam se referindo ao trabalho com conteúdos posteriores aos da Matemática básica, quando se insinua, mais intensamente, certo formalismo que não caracteriza, geralmente, o tratamento aos conteúdos iniciais do Ensino Básico. 
passado por uma formação específica para exercício do magistério. Alguns dos professores desses nossos depoentes desempenharam papel importante na escolha da disciplina matemática. Em alguns casos, esses mesmos professores indicavam seus alunos - nossos colaboradores - para assumirem aulas em determinada escola.

Alguns desses professores contavam com formação em nível superior, o que revela que o interior do estado de São Paulo já começava, na década de 1950, a contar com professores graduados em instituições de Ensino Superior, ainda que os cursos universitários tenham começado a espalhar-se com mais ênfase, no interior do estado, na década de 1960 (BARALDI, 2003).

Como nas décadas de 1950 e 1960 o Ensino Secundário estava se impondo maciçamente e o interior do estado de São Paulo ainda não contava com Licenciaturas, realizar cursos era a alternativa para complementar a formação básica. A realização desses cursos foi determinada ora por exigências legais ou indicação da direção da escola, ora por escolha do professor.

Nesta etapa de formação intermediária nossos depoentes fizeram referência à realização de cursos específicos, como os de soroban, Matemática Moderna e CADES. Como esses cursos eram realizados quando o professor já estava lecionando, muitas são suas relações com a formação na prática.

O uso do soroban foi uma estratégia didática muito comum no ensino agrícola, embora nem todos os professores depoentes o tenham utilizado. A divulgação desse recurso foi atribuída ao Shigueo Mizoguchi, seja na escola agrícola de Presidente Prudente, seja em maior escala, para todas as escolas do sistema agrícola, quando ele assumiu a Diretoria Estadual de Ensino Agrícola.

Os cursos de soroban foram realizados em convênio com o Centro Nacional de Aperfeiçoamento de Pessoal para a Formação Profissional (CENAFOR). A intenção era a de que os professores de matemática frequentassem esses cursos e destinassem algumas aulas para o ensino e a prática de atividades utilizando esse recurso. Por terem sido oferecidos por um curto período, e devido ao afastamento de Shigueo Mizoguchi da direção do ensino agrícola, nem todos os professores chegaram a frequentá-los. Também foram organizados campeonatos estaduais de soroban entre escolas agrícolas. Ainda que ao técnico agrícola nem sempre fossem necessárias operações matemáticas muito complexas, ter um bom raciocínio poderia auxiliá-lo na tomada de decisões rápidas e eficazes em sua atuação profissional. O objetivo do trabalho com o soroban, portanto, era levar os alunos a essa agilidade no raciocínio.

Em relação às estratégias para o ensino de matemática, além do uso soroban por alguns professores, foram destacadas tanto as aulas desenvolvidas pelo docente, a partir de exposição da matéria em lousa e listas de exercícios de fixação individuais, quanto as situações de monitoria com alunos mais habilidosos em matemática. Foram citadas, também, a importância ou validade dos problemas de aplicação, das competições entre classes e as participações em olimpíadas e campeonatos.

No caso das escolas que adotaram o soroban, a participação nos campeonatos foi destacada nos depoimentos, sobretudo se algum estudante conseguiu boa classificação. Este fator nos leva a perceber artifícios para o enfrentamento de uma marginalidade não declarada, mas de algum modo percebida. Conseguir que alunos se destacassem no campeonato era uma maneira de mostrar as potencialidades do ensino agrícola que sofria com a comparação em relação ao ensino regular. 
Na década de 1960 - quando se intensificou a aproximação entre o ensino técnico e o ensino regular -, temos o momento em que modificações significativas em relação ao ensino de matemática chegam até as escolas agrícolas. A introdução dos conteúdos na perspectiva da matemática moderna foi destacada como um momento novo nessas escolas, pautado pela abordagem dos conteúdos matemáticos pela via da teoria dos conjuntos.

Os cursos relativos à matemática moderna foram procurados por alguns professores depoentes e outros foram se aproximando desse novo modo de trabalhar a matemática por meio dos livros didáticos disponíveis. Alguns professores não realizaram treinamentos específicos e a adaptação foi sendo realizada aos poucos.

Ao ver um anúncio do jornal O Estado de São Paulo a respeito de um curso de matemática moderna, dona Noriko saiu de Presidente Prudente para São Paulo, de trem, sozinha, sem conhecer a capital, para inscrever-se e frequentar o curso, oferecido pela Universidade de São Paulo. A USP, para essa professora, era totalmente desconhecida no que diz respeito tanto às instalações quanto à importância atribuída a esta instituição no panorama educacional do país. Somente mais tarde a professora Noriko percebeu ser esta universidade de renome: relata, inclusive, que se soubesse disso anteriormente, se conhecesse o que esta universidade era ou o que ela representava, não teria tido coragem de ir até lá. Este relato nos faz refletir sobre certa distância entre as instituições de Ensino Superior e as de Ensino Básico. Ainda que em geral, hoje, instituições de renome sejam as mais procuradas, para muitos professores esse pode ser um motivo de percebê-las como inacessíveis.

Para essa professora, a maior diferença entre o ensino regular e o agrícola pode ser percebida quando da introdução da matemática moderna. No curso do segundo grau agrícola não se trabalhava esse assunto, era enfatizada a matemática financeira elementar: juros e porcentagens para cálculo de produção agrícola. As atividades relativas à matemática moderna, desenvolvidas no ginásio, também indicavam a necessidade de alterações quanto à linguagem: no ensino agrícola, para atender a essas diretrizes, alguns professores usavam conjuntos "contendo animais". A preocupação com a necessidade de adequação da linguagem (e não só da linguagem) era comum na escola agrícola. Trabalhar a matemática a partir do e para conhecer o mundo concreto: usava-se, por exemplo, para a operação de divisão, a repartição de frutas entre membros de uma família, o que se julgava mais próximo à linguagem e realidade dos alunos. A professora Noriko, após contato com a teoria dos conjuntos, buscava, para sua sala de aula, alternância entre uma linguagem mais abstrata e uma mais próxima à realidade dos alunos. Essa adequação devia-se tanto às necessidades dos alunos quanto ao próprio universo do professor, cuja formação era lacunar. Ainda durante o curso, Noriko percebeu a ênfase na linguagem da teoria dos conjuntos, procurando apreender diferenças, por exemplo, entre adição e união, pois tudo para ela era novidade, e destacou que, mesmo no início da década de 1960, em seus cursos pela CADES, essa abordagem "moderna" já havia se manifestado.

Para a professora Edith, que se iniciou na matemática moderna sem realizar cursos, esse era apenas um novo método, que mais apavorou os pais dos alunos devido à introdução de uma nova simbologia e de um modo diferente de se abordarem os mesmos conteúdos. A professora Maria Peres não se recorda de cursos referentes à matemática moderna, mas destaca que foi introduzindo, aos poucos, em suas aulas, algumas ideias novas, que julgava serem necessárias para atender às mudanças nas legislações, mas que, em geral, não traziam boas contribuições. 
Os professores que se referiram à matemática noderna a relataram como um modo diferente de ensinar os mesmos conteúdos matemáticos, e poucos foram os impactos por eles percebidos, especialmente nas escolas agrícolas. De certo, porém, temos que a matemática moderna e sua aplicação nas escolas agrícolas é um sintoma visível da equiparação, por força de lei, tanto dos níveis de ensino quanto da natureza do que se deveria ensinar nas escolas, independente de suas orientações específicas. Entretanto, se algumas práticas alteram-se, outras permanecem...

A legislação que determinava o funcionamento do ensino agrícola na década de 1950, quando alguns de nossos depoentes iniciaram atividades docentes em escolas agrícolas, era a Lei Orgânica do Ensino Agrícola, de 1946, que vigorou até 1961. Nesse período, porém, a equiparação entre o ensino agrícola e o regular foi determinada pela Lei de Equivalência do início da década de 1950, que estabelecia a grade curricular comum para ambos os sistemas de ensino. A LDB de 1961 (cf. ROMANELLI, 1978) consolida a equiparação com a criação dos ginásios e colégios agrícolas. Em 1967, por meio de Decreto ${ }^{11}$, o Governo Federal estabeleceu a transferência dos órgãos de ensino vinculados ao Ministério da Agricultura para o MEC, o que, como decorrência, implicou também alteração no ensino agrícola paulista. Essas mudanças legais, no entanto, não extinguiram práticas que vigoravam em algumas escolas quanto aos modos de conduzir as disciplinas. Devido a diferenças nos cursos oferecidos em cada escola, antes da LDB de 1961, os modos como a disciplina matemática era ali conduzida também diferiam, o que influenciou práticas posteriores a esta legislação.

$\mathrm{Na}$ tentativa de atender às necessidades do ensino agrícola foram apontados alguns recursos utilizados para a preparação das aulas de matemática, como: livros, uma programação da grade curricular publicada no Diário Oficial da União, e "muita criatividade". O apoio dos livros didáticos foi apontado como um modo de o professor preparar-se para ensinar um conteúdo, ou para que, a partir do livro, fosse possível uma adaptação à realidade da escola agrícola.

Os professores relataram a inexistência de livros destinados à realidade do ensino agrícola, como havia para os cursos industrial e comercial. Realizamos uma busca a respeito de livros com essa indicação dentre os quase mil exemplares de livros antigos do acervo do GHOEM (Grupo de Pesquisa "História Oral e Educação Matemática"), e não detectamos nenhum cuja recomendação vinculasse seu uso aos cursos agrícolas. No máximo, a indicação genérica "e para outros cursos técnicos". O que pudemos identificar foi a existência de alguns conteúdos que se aplicavam à realidade agrícola, como, por exemplo, as unidades de medidas agrárias.

Devido à inexistência de materiais específicos para a preparação das aulas, a alternativa dos professores era basear-se em livros didáticos "gerais" e outros materiais existentes, sendo que as adaptações feitas, segundo as narrativas coletadas, referiam-se mais à "linguagem". Os problemas de aplicação de conceitos matemáticos sempre eram elaborados ou reelaborados com cuidado para que a linguagem fosse acessível aos alunos da escola agrícola. Tal cuidado também foi por nós detectado entre os professores que atuaram em escolas rurais primárias da região de Bauru nas décadas de 1950 e 1960 (MARTINS, 2003).

${ }^{11}$ Decreto n. 60.731, de 19 de maio de 1967. 
Em Presidente Prudente, a matemática ministrada no curso de liderança rural foi descrita como elementar, enfatizando números decimais, ainda que se buscasse seguir a mesma grade do ensino regular. Havia relação dos conteúdos matemáticos com outras matérias, como em economia doméstica. Nesta disciplina, os professores sempre pediam "uma revisão" sobre porcentagens, sistemas de medidas, conversões de medidas, números decimais e frações, conceitos tidos como muito utilizados em atividades de culinária. Havia, nessa escola, um acompanhamento constante das atividades pelo diretor Shigueo Mizoguchi, cujas recomendações eram para que se abordassem conteúdos sempre com aplicação na área técnica visando a suprir as necessidades práticas daqueles que iriam trabalhar com a agricultura. A experiência (a lida no campo) asseguraria o não esquecimento do aprendido. A professora Madalena também destaca a influência desse diretor na condução dos trabalhos, afirmando que ele projetava um ensino agrícola como uma superestrutura, uma fazenda modelo na qual os alunos aprendessem práticas que pudessem, futura e efetivamente, implantar em suas propriedades particulares ou onde fossem trabalhar. Nessa fazenda haveria, por exemplo, uma produção em retroalimentação - com reaproveitamento de dejetos e sobras como adubo - cujo potencial seria maximizado pela produção em série.

Para os professores que trabalharam mais próximos ao senhor Shigueo, ele demonstrava domínio de todas as áreas, inclusive em matemática, o que lhe permitia orientar os professores. Compreendia, portanto, quando não era possível realizar adaptações. Para a professora Noriko, a maior dificuldade de aplicação estava na geometria, que se reduzia ao estudo de área, perímetro e volume.

Ainda que outros conteúdos de matemática tenham sido trabalhados, foram destacados: perímetro, área (inclusive de terrenos irregulares, em que os alunos deveriam buscar a maximização do terreno a ser cultivado), volume, números decimais, conversão de medidas, teorema de Pitágoras, composição e decomposição de figuras para cálculo de área, regra de três, porcentagens, juros (funcionamento do sistema bancário), funções trigonométricas (seno, cosseno, tangente e cotangente, utilizados em topografia). Procurava-se cumprir toda a grade curricular.

$\mathrm{Na}$ prática, buscava-se a equivalência do ensino agrícola com os cursos regulares, solicitando aumento do número de aulas, inclusão de aulas de desenho geométrico e de reforço. Essas eram formas de dar oportunidades, aos alunos do curso agrícola, de ter contato com recursos específicos da geometria, compreender os conceitos para além das formas analíticas e usar o tempo mais adequadamente, em atividades de reforço e aprofundamento.

Embora a maior procura pelas escolas agrícolas se devesse à parte técnica, do ponto de vista dos demais conteúdos procuravam-se desenvolver as mesmas ementas, ainda que o número de aulas fosse menor. Com a implantação dos ginásios agrícolas após 1961, a quantidade dessas aulas aumentou, mas até hoje continua menor no colégio agrícola em relação ao Ensino Médio regular. Devido à carga horária ser menor, tornava-se difícil abarcar todo o conteúdo, pois era necessário enfatizar conteúdos mais utilizados pela área técnica. Mesmo assim, segundo os depoimentos coletados, grande esforço era feito para que os alunos das escolas agrícolas tivessem contato com todos os conteúdos matemáticos.

Também, segundo os depoimentos, tal esforço parece ter sido recompensado pelas atividades que atestaram essa equiparação, particularmente pelas boas colocações dos alunos em olimpíadas, campeonatos e gincanas envolvendo matemática. A professora Elda recordou 
de uma gincana de matemática realizada entre escolas da região de São Manuel, da qual os alunos da escola agrícola participaram conquistando o primeiro ou segundo lugar na competição. Esta classificação foi, inclusive, melhor do que a da que era considerada a escola "forte" na cidade.

A participação nas Olimpíadas de Matemática foi destacada pelo professor Oduvaldo. No ano de 1967 ele participou, pela primeira vez, com alunos da escola agrícola, das Olimpíadas de Matemática. Mesmo sem conhecer a estrutura das provas e a natureza das Olimpíadas, foram bem classificados. Em 1969, participaram pela segunda vez, agora tanto na categoria individual quanto por equipe, e novamente obtiveram excelentes classificações, inclusive primeiros lugares. O bom desempenho dos alunos nas Olimpíadas, segundo o professor Oduvaldo, deveu-se ao trabalho com alunos monitores na sala de aula - aqueles com melhor rendimento em matemática auxiliavam as atividades dos menos habilidosos, o que fazia com que estudassem e se aperfeiçoassem ainda mais.

Essa participação nos concursos e as boas colocações alcançadas são julgadas como extremamente representativas, inclusive por terem tido destaque na imprensa. Devido a essa representatividade, membros do Grupo de Estudo de Ensino da Matemática (GEEM) visitaram a escola e a cidade, com isso se conseguiu, inclusive, uma promessa, feita pela Secretaria da Educação, de que o nível ginasial não seria extinto - promessa que, por um tempo, foi possível manter. Mas o fechamento foi inevitável nos primeiros anos da década de 1970. Tal situação exemplifica a intensidade com que algumas legislações se manifestaram no ensino agrícola: por mais que ações internas à escola justificassem a manutenção da estrutura - uma vez que bons resultados vinham sendo obtidos - estes não foram suficientes para deter a reestruturação determinada pela lei que, em 1971, tornava compulsória a profissionalização apenas para o segundo grau.

Além do empenho dos professores, também a dedicação aos estudos, demonstrada por muitos alunos, contribuía para a equiparação da escola agrícola com as escolas de ensino regular. Por esse motivo julgava-se importante a estruturação do currículo tomando, como base, a mesma grade adotada no ensino agrícola, mesmo antes da determinação da equivalência. Nesse sentido, os livros disponíveis desempenharam importante papel no desenvolvimento dessa disciplina, sendo que autores como Osvaldo Sangiorgi e Scipione de Piero Neto foram referenciados pelos depoentes. A preparação de aulas com os livros didáticos ou em parceria com professores da área técnica, buscando uma adequada grade curricular, parece ter sido um ingrediente significativo em relação à formação em serviço dos professores de matemática que passaram por escolas agrícolas.

Essa possibilidade de organização curricular que seguia a mesma grade do ensino regular - ou ao menos era pautada por ela - nos permite perceber diferentes dimensões: ao mesmo tempo em que permitia certa liberdade para o planejamento de acordo com as necessidades do ensino agrícola, sentia-se falta de uma liderança e orientações claras aos profissionais dessas instituições. Padeciam pela comparação em relação ao ensino regular, tentavam adequar-se às determinações impostas aos cursos regulares, mas mantinham-se na periferia das alterações efetivas: marginalizavam-se. Ao mesmo tempo em que se marginalizavam, porém, construíam modos de subverter a situação, procurando saídas para atender a um sistema de gerenciamento que deveria - mas não o fazia - aplicar-se na defesa da igualdade de condições e de oportunidades. 
Nesse cenário um tanto caótico do ponto de vista de gerenciamento, inclusive pelas sucessivas mudanças de gestão, foi possível identificar indícios de outra marginalidade interna às escolas agrícola: a marginalidade sentida pelos professores das áreas não técnicas, uma vez que as preferências sempre eram dadas aos professores das áreas técnicas. Tal situação foi por nós percebida como sendo uma marca a mais na cadeia de marginalizações.

Mas esse era um espaço de trabalho, e era necessário adequar-se. E, então, a formação do professor de matemática extrapola a instrumentalização ou o conhecimento dos conteúdos específicos: é uma formação que passa pelas relações de poder no interior dos ambientes de trabalho. Nos depoimentos podemos perceber diferentes posturas dos professores de matemática nas relações com os demais profissionais.

Em algumas escolas agrícolas, como em Jaboticabal e em Presidente Prudente, o planejamento dos conteúdos da disciplina matemática era realizado pelo professor de matemática juntamente com professores das áreas técnicas, como agrônomos e veterinários. $\mathrm{O}$ objetivo, nesses casos, era priorizar os tópicos a serem aplicados efetivamente na formação de viés mais prático. As mudanças na legislação, para essas escolas, pouco alteraram o papel da matemática, que continuou sendo uma ferramenta para o desenvolvimento das disciplinas da área técnica. Esse modo de trabalhar com a disciplina apresenta fortemente uma concepção que se refere à aplicabilidade dos conteúdos escolares.

Em Espírito Santo do Pinhal, a professora Maria Peres não planejava a distribuição dos conteúdos juntamente com os demais profissionais, mas buscava informações quando os alunos lhe perguntavam sobre particularidades em relação à aplicação da matemática em atividades da agricultura. Em outras situações percebia que alguns alunos pretendiam seguir carreiras em outras áreas, por isso se empenhavam mais nos conteúdos das matérias não técnicas.

Em outras escolas agrícolas, no período de atuação de nossos depoentes, não ocorreu essa articulação entre a disciplina matemática e as especificidades técnicas. Em Jacareí e em São Manuel, pelo menos no período de atuação das professoras Edith e Elda, respectivamente, a ideia de aplicação não se manifesta como atividade conjunta entre as áreas. A matemática desenvolvida ali não levava em consideração as necessidades de aplicação. Dona Elda assinala que ensinavam "a matemática do livro" e que as aplicações, quando necessárias, ocorriam nas aulas das matérias técnicas. Essa seria, segundo ela, uma das justificativas do maior interesse dos alunos pelas disciplinas da área técnica.

De acordo com a professora Madalena, o planejamento entre as áreas e a aplicação da matemática na área técnica eram mais intensos quando trabalhou em Presidente Prudente sob a direção de Shigueo Mizoguchi. Mas podemos detectar que, em Jaboticabal, à época do professor Oduvaldo, essa necessidade também se manifesta, ainda que assumindo postura mais igualitária no planejamento, negociando com outros profissionais a distribuição dos conteúdos.

O desenho geométrico não fazia parte da grade curricular em Jacareí, mas Edith incluía os conteúdos nas aulas de geometria. Já Maria Aparecida, em Espírito Santo do Pinhal, lutava para que essa disciplina fosse incluída na grade curricular. Tal solicitação justificava-se por um duplo objetivo: por um lado, dar oportunidades aos alunos da escola agrícola de estudá-los, e, por outro, aumentar o número de aulas que poderiam ser ministradas pelos professores de matemática, o que garantiria certa vantagem no momento da escolha. Suas reivindicações, após muita insistência, algumas vezes foram atendidas e houve remuneração pelas atividades extras. 
Em Jaboticabal, o professor Oduvaldo relata uma preocupação com a aplicação de conteúdos matemáticos à realidade da escola agrícola, dos fazeres do campo e das práticas rurais, fazendo planejamento juntamente com os profissionais da área técnica. O professor Oduvaldo escreveu um livro de matemática, não publicado, a partir do qual preparava suas aulas. Fazia adaptações em exercícios para aplicá-los à escola agrícola.

No caso da escola de Presidente Prudente, nos primeiros anos de funcionamento, no curso de liderança rural, as atividades matemáticas eram desenvolvidas de modo elementar pelos diretores Shigueo Mizoguchi e Cid Haroldo Corrêa (respectivamente, agrônomo e veterinário). O senhor Cid destacou que suas formações possibilitavam ministrar essas aulas. Um pouco depois, quando o curso já estava mais bem organizado, a professora Noriko foi contratada para trabalhar com matemática. Recém-formada, ao se deparar com esta realidade, optou por acatar as sugestões do diretor e procurava orientação dos professores da área técnica para planejar suas aulas conforme as necessidades daquela área, atuando, inclusive, em aulas extras de soroban sem remuneração.

Tal situação era mais sentida antes da implantação dos ginásios agrícolas, pois com eles a equivalência com o ensino regular tornou-se definitiva, ainda que em Presidente Prudente tenha se mantido uma forte tendência para a aplicação da Matemática na área técnica. A professora Madalena enfatizou que, quando iniciou nessa escola, ainda era solicitada, pelo diretor, a distribuição dos conteúdos de matemática visando a atender a formação esperada nos cursos agrícolas: sua orientação era para que os alunos fossem preparados de acordo com as suas futuras carreiras, e essas "futuras carreiras" poderiam ser relacionadas à atuação como agentes de produção (trabalhariam como produtor em terras próprias ou não), agentes de serviços (lidariam com a comercialização e orientação quanto ao uso de insumos e defensivos agrícolas) ou, ainda, relacionadas à sequência da vida acadêmica.

Essa busca pela integração entre as áreas e a aplicação da Matemática às necessidades das atividades específicas daqueles que iriam trabalhar com a agricultura ou em seu entorno parece ter sido mais específica em Presidente Prudente. No período em que o senhor Shigueo esteve na direção geral do ensino agrícola, é possível perceber a disseminação de suas ideias em relação a essa modalidade de ensino. Suas influências manifestam-se, por exemplo, como já explicitado, na adoção do soroban e no modelo escola-fazenda para as escolas agrícolas.

Ainda que essa formação na prática pareça ter influenciado o desenvolvimento do ensino agrícola e dos professores de matemática que ali atuavam, uma outra formação complementar, pela qual passaram os professores depoentes, foi a da CADES, devido a uma exigência legal. Com os cursos oferecidos, obtinha-se um registro temporário que permitia o exercício do magistério em cursos secundários nos locais onde não houvesse instituições de nível superior próximas.

Essa foi uma formação provisória também em outros estados, como apontado por Cury (2007), que estudou o histórico das Licenciaturas em Matemática no estado de Goiás e, mais especificamente, por Gaertner (2004), em seu estudo sobre a escola alemã (Neue Deustche Schule), em Santa Catarina.

Devido a essa exigência legal e/ou ao desejo de continuidade nos estudos, o perfil dos professores de matemática foi se alterando, passando da formação secundária e complementar a uma formação universitária, com especificidade de disciplina. Dentre os professores depoentes nessa pesquisa, alguns cursaram Licenciatura em matemática, em história, em geo- 
grafia, filosofia, medicina veterinária, teologia, pedagogia e administração escolar. Relataram diferentes relações com a disciplina matemática em sua formação, seja no Normal, Científico ou ainda em cursos como o da CADES e na própria Licenciatura.

Para alguns de nossos depoentes, a opção mais fácil para cursar instituições de nível superior buscando formação específica foi ingressar em faculdades de outros estados, devido à proximidade com os cursos universitários. Para a professora Noriko, em Presidente Prudente, a opção foi a cidade de Jacarezinho, no Paraná, distante mais de duzentos quilômetros, o que a obrigava a cansativas viagens diárias. Já a professora Maria Peres, de Espírito Santo do Pinhal, teve uma opção mais próxima do que Campinas, no município de Poços de Caldas, em Minas Gerais. Em ambos os casos, já estava sendo oferecida a Licenciatura em matemática em suas cidades de origem, mas o funcionamento desses cursos no período diurno as impedia de frequentá-los por já lecionarem na escola agrícola nesse período. Os demais professores-colaboradores cursaram suas Licenciaturas em matemática em suas cidades ou nas vizinhanças: a professora Edith, de Jacareí, licenciou-se em Guarulhos; o professor Oduvaldo viajava de Jaboticabal para Ribeirão Preto para fazer sua graduação; já a professora Madalena graduou-se em Presidente Prudente, cidade na qual residia.

\section{Sintetizando}

De um ponto de vista interno às escolas, tomando como lentes os depoimentos dos professores, marcas de marginalidade puderam ser percebidas. Particularmente, as percebemos em relação ao papel da disciplina matemática e de seus professores quando se insistia numa comparação entre a formação dos técnicos agrícolas e os programas das escolas urbanas de ensino regular. Essa foi uma marginalidade um tanto quanto transitória, uma vez que a determinação da equivalência entre os sistemas de ensino, ao mesmo tempo em que retirou a especificidade dessas formações, promoveu a equiparação dos conteúdos escolares relativos à Matemática. Mas para reverter um cenário em que as escolas técnicas agrícolas eram vistas como estando num segundo plano em relação ao ensino regular, alguns dos professores das escolas agrícolas participavam, conscientemente ou não, de uma luta para divulgar as vantagens e potencialidades dessa modalidade de ensino, não apenas em relação à formação técnica, mas também em relação à formação em geral: uma das estratégias empregadas era a divulgação de bons resultados obtidos por alunos dessas escolas em competições "matemáticas". Por outro lado, mesmo dentro das escolas agrícolas, todo um universo de exclusões, aproximações e apropriações pode ser detectado, dado que - até por força dos mecanismos de legislação e controle implantados - imperavam as determinações das disciplinas técnicas, sendo a matemática uma coadjuvante cujos professores precisariam alinhar-se aos professores de formação técnica.

Pudemos ainda perceber vestígios de que essa resistência à marginalização da escola agrícola ainda se mantém. Isso ocorre quando destacam alunos que, tendo sido formados em Escolas Agrícolas, foram e são reconhecidos nas profissões que escolheram, ligadas ou não à agricultura. O sucesso e reconhecimento obtido por esses profissionais foram apontados como uma comprovação de que a formação desenvolvida em escolas agrícolas não era aquém à do ensino regular. 
Escolas Técnicas Agrícolas: um estudo ...

Constituído esse cenário, buscamos olhar para qual foi a formação necessária ou por qual formação passaram os professores de matemática que nele atuaram. A formação inicial mostrou-se muito similar a de outros professores que atuaram no sistema de ensino regular, basicamente a do curso Normal e Científico, complementada com cursos em serviço - uma formação lacunar, sem especificidades, pouco atrelada à prática e ao que era divulgado como sendo as necessidades da formação do técnico agrícola.

A diferença na formação do professor que lecionou matemática nas escolas agrícolas deveu-se, basicamente, a sua formação na prática, sobretudo para aqueles que se depararam com a necessidade de adequação ou aplicação dos conteúdos matemáticos às necessidades da área técnica. Neste sentido, esses professores fogem a uma tendência dentre os professores em início de carreira - a de reproduzir práticas de seus antigos professores. E essa é uma das faces da marginalidade: ao mesmo tempo em que o isolamento é forçado, surgem as possibilidades e os exercícios de superação. Se por um lado não contavam, nessas escolas, com apoio externo para sua organização pedagógica, tal situação era revertida em autonomia e construção de um modo próprio, ou pelo menos diferenciado, de se tornar professor de matemática.

\section{Referências}

BARALDI, I. M. Retraços: uma história da formação de professores de Matemática na região de Bauru. 2003. 240f. Tese (Doutorado em Educação Matemática) - Instituto de Geociências e Ciências Exatas, Universidade Estadual Paulista, Rio Claro, 2003.

BRASIL. Decreto n. 60.731, de 19/05/1967. Dispõe sobre a transferência para o Ministério da Educação e Cultura os órgãos de ensino do Ministério da Agricultura. Caderno de Leis. Brasília, DF, 1967.

Lei de Diretrizes e Bases da Educação Nacional. Brasília, DF, 1961.

. "Lei de Equivalência". Caderno de leis. Brasília: Divisão do Ministério de

Educação e dos Desportos, 1951.

Decreto-lei n. 9.613, de 20/08/1946. Dispõe sobre as bases de organização e de regime do Ensino Agrícola (Lei orgânica do Ensino Agrícola). Caderno de Leis. Brasília, DF, 1946.

CANDIDO, A. Os parceiros do Rio Bonito. São Paulo: Duas Cidades/Ed. 34, 2003.

CUNHA, L. A. O ensino de ofícios nos primórdios da industrialização. São Paulo: Editora Unesp, 2005a.

O ensino de ofícios artesanais e manufatureiros no Brasil escravocrata. São

Paulo: Editora Unesp, 2005b. 
Martins-Salandim, M. E.; Garnica, A. V. M.

CURY, F. G. Uma narrativa sobre a formação de professores de Matemática em Goiás. 2007. 201f. Dissertação (Mestrado em Educação Matemática) - Instituto de Geociências e Ciências Exatas, Universidade Estadual Paulista, Rio Claro, 2007.

DEL PRIORE, M.; VENÂNCIO, R. Uma história da vida rural no Brasil. Rio de Janeiro: Ediouro, 2006.

ELIAS, N. Os estabelecidos e os outsiders: sociologia das relações de poder a partir de uma pequena comunidade. Rio de Janeiro: Jorge Zahar, 2000.

GAERTNER, R. A matemática escolar em Blumenau (SC) no período de 1889 a 1968 : da Neue Deutsche Schule à Fundação Universidade Regional de Blumenau. 2004. 350f. Tese (Doutorado em Educação Matemática) - Instituto de Geociências e Ciências Exatas, Universidade Estadual Paulista, Rio Claro, 2004.

GALETTI, I. P. Educação matemática e nova alta paulista: orientação para tecer paisagens. 2004. 187f. Dissertação (Mestrado em Educação Matemática) - Instituto de Geociências e Ciências Exatas, Universidade Estadual Paulista, Rio Claro, 2004.

GARNICA, A. V. M.; MARTINS, M. E. Educação e educação matemática em escolas rurais do oeste paulista: um olhar histórico. Zetetiké, Campinas, v. 1, n. 14, p. 29-64, 2006.

HOLANDA, S. B. Raízes do Brasil. São Paulo: Companhia da Letras, 2006.

MARTINS, M. E. Resgate histórico da formação e atuação de professores de escolas rurais: um estudo no oeste paulista. 2003. 261f. Relatório (Iniciação Científica) - Fapesp, Departamento de Matemática, Universidade Estadual Paulista, Bauru, 2003.

MARTINS-SALANDIM, M. E. Escolas Técnicas Agrícolas e educação matemática: história, práticas e marginalidade. 2007. 265f. Dissertação (Mestrado em Educação

Matemática) - Instituto de Geociências e Ciências Exatas, Universidade Estadual Paulista, Rio Claro, 2007.

PINTO, A. H. Educação matemática e formação para o trabalho: práticas escolares na Escola Técnica de Vitória. 2006. 190 f. Tese (Doutorado em Educação Matemática) Faculdade de Educação, Universidade Estadual de Campinas, Campinas, 2006.

ROMANELLI, O. História da educação no Brasil 1930-73. Petrópolis: Vozes, 1978.

SCHMITT, J. C. A história dos marginais. In: Le GOFF, J. (Org.). A história nova. São Paulo: Martins Fontes, 2001. p. 260-289.

Artigo recebido em julho de 2009 e aceito em dezembro de 2009. 